\title{
AMBĀ: LA VENGANZA FEMENINA EN EL MAHĀBHĀRATA
}

\author{
Roberto Morales Harley
}

\section{(c) $(7) \Theta$}

Doi: https://doi.org/10.15517/rfl.v46iEspecial.41638

URL: https://revistas.ucr.ac.cr/index.php/filyling/index 



\title{
AMBĀ: LA VENGANZA FEMENINA EN EL MAHĀBHĀRATA
}

\author{
AMBĀ: FEMININE VENGEANCE

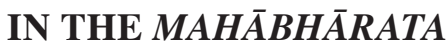

Roberto Morales Harley

\begin{abstract}
RESUMEN
Ambā es un personaje femenino que es agraviado por Bhīṣma y que, posteriormente, toma venganza por cuenta propia como el personaje masculino Śikhaṇịin. El trabajo contextualiza la posición de las mujeres, tanto en la India antigua como en la literatura épica sánscrita, y analiza el mito en su fuente sánscrita (MBh. I, 94-100; V, 170-197; VI, 108-119), a partir de la terminología para referirse a la "venganza" (pratikāra) y a la "femineidad" (strītva).

Palabras clave: Ambā; Śikhaṇḍin; mitología hindú; épica sánscrita; Mahābhārata.
\end{abstract}

\begin{abstract}
Ambā is a female character who is wronged by Bhīṣma and who, later, takes revenge by her own means as the male character Śikhaṇ̣in. The paper contextualizes the position of women, both in ancient India and in Sanskrit Epic literature, and analyzes the myth in its Sanskrit source (MBh. I, 94-100; V, 170-197; VI, 108-119), based on the terminology used for "vengeance" (pratikära) and "womanhood" (strītva).
\end{abstract}

Keywords: Ambā; Śikhaṇdin; hindu mythology; sanskrit epics; Mahābhārata.

\section{Introducción}

Ambā es un personaje femenino del Mahābhārata, el gran poema épico de la literatura sánscrita que narra la lucha entre Pāṇḍavas y Kauravas por el reino de Kurukṣetra. Según Mani (1975, pp. 27-29), los momentos clave de su participación en la epopeya son los siguientes: Ambā es considerada como una posible esposa para Vicitravīrya, el joven heredero del reino; Bhīṣma, el abuelo de los Pāṇḍavas y los Kauravas, la rapta de su svayamvvara (matrimonio por elección), en el cual se habría de casar con el rey Sālva; Sālva, a su vez, la rechaza por haber sido raptada por Bhīṣma; Ambā, entonces, jura vengarse de Bhīṣma y, para ello, obtiene, mediante su ascetismo, el favor del dios Śiva; así, Ambā reencarna como el personaje femenino

M. L. Roberto Morales Harley. Profesor de la Escuela de Filología, Lingüística y Literatura. Universidad de Costa Rica. Costa Rica. Correo electrónico: roberto.moralesharley@gmail.com

Recepción: 20- 06- 19

Aceptación: 10- 12- 19 
Śikhaṇdinī, para luego convertirse en el personaje masculino Śikhanḍin, en un nuevo contexto de boda; finalmente, participa en la muerte de Bhīṣma a manos de Arjuna, con lo que ejecuta su ansiada venganza.

La literatura sánscrita está llena de personajes femeninos que son considerados modelos de conducta. Para referirse a ellos, se emplea el término satı̄ (esposa fiel), derivado de la raíz AS (ser), el cual designaba, en principio, a una mujer 'que es como debe ser', es decir, 'que es buena', principalmente en relación con su esposo. Con el paso del tiempo, ocurrió una restricción del sentido (Monier-Williams, 2008, p. 1135) y sat̄̄ pasó a designar a una mujer 'que se arroja viva a la pira fúnebre de su esposo' y, por extensión, a la práctica social de la 'inmolación de la viuda', que mantuvo su legalidad hasta 1829 (Vofchuk, 2016, p. 121).

Pese a que "no se ha podido hallar un lugar y un momento preciso en que haya tenido origen esta práctica tradicional hindú" (Vofchuk, 2016, p. 119), según las fuentes arqueológicas, esta costumbre se remonta a una inscripción del 510 a. C., hallada en la ciudad de Eran, estado de Madya Pradesh, donde se habla de la esposa del rey Bhanugupta en estos términos: "aquella esposa amante y adorada se echó a las llamas al lado de los despojos de su marido" (Auboyer, 1974, p. 224).

De acuerdo con los testimonios literarios, podría ser incluso más antigua, si se toma como precedente el $\operatorname{Rg}$ Veda $(\mathrm{X}, 18,7)$ :

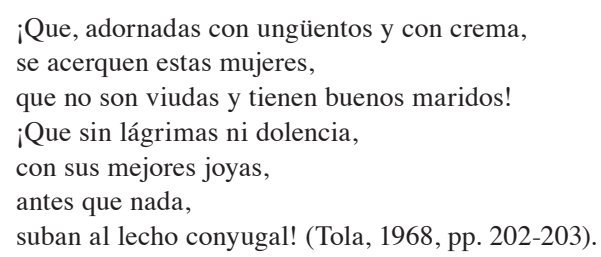

Este himno de carácter funerario menciona un 'lecho conyugal', en el cual se ha querido ver una alusión a la pira funeraria. De este modo, sus versos "fueron utilizados como argumentos para dar un origen divino a la costumbre de que las viudas se quemaran junto con sus esposos muertos" (Tola, 1968, p. 200). Sin embargo, el sentido de la frase es simbólico: se refiere al lecho de un segundo esposo vivo y no al del primer esposo muerto. De hecho, en la estrofa siguiente se contextualiza la acción en el jīvalokám (mundo de los vivos).

En la tradición hindú, la sat̄̄ (esposa fiel) es aquella que cumple con el pativratā dharma (deber de la esposa devota). El dharma, concepto central del Hinduismo, remite, a la vez, al 'deber moral', a la 'ley social' y al 'orden cósmico'. En el caso de la mujer, su deber en función del mundo y de la sociedad consiste en ser pativrata (esposa devota), esto es, una mujer 'que respeta a su esposo como si se tratara de un dios'. El término pativratā, se compone del sustantivo pati (esposo) y el sustantivo vrata (devoción), derivado, a su vez, de la raíz VR (elegir).

La sat̄̄ (esposa fiel) por excelencia, en la literatura sánscrita, es Sîtā, personaje femenino del Rāmāyaṇa, cuya fidelidad hacia su esposo Rāma es tal que incluso acepta someterse a un juicio por fuego a fin de probarla. Si se toma en cuenta, como modelo griego de la fidelidad, a Penélope, cuya prueba por parte de Odiseo se limita al plano de sus palabras, es posible vislumbrar la dimensión de la fidelidad exigida a este modelo indio, del cual se esperan también acciones. Penélope está dispuesta a entregar los mejores años de su vida; pero Sîtā, su vida misma. 
Sītā y otras esposas fieles han llamado la atención de la crítica (Shah, 2012, p. 77), no solo por parte de los estudiosos europeos, como la periodista francesa Clarisse Bader ( $L a$ femme dans l'Inde antique, 1864) y el indólogo alemán Johann Meyer (Sexual Life in Ancient India, 1915); sino también de los historiadores indios, como Ramesh Majumdar (Ideal and Position of Indian Women in Domestic Life, 1953) y Vasudeva Agrawal (Bharat Savitri, 1957).

Especial interés han despertado estos personajes en la crítica feminista, la cual ha enfatizado la "ideología patriarcal” (Shah, 2012, p. 78, traducción propia) que subyace a estos planteamientos: Meenakshi Mukherjee (Deadweight of Tradition: The Sita-Savitri Ideal, 1979), Uma Chakravarti (The Development of the Sita Myth: A Case Study of Women in Myth and Literature, 1983), Sally Sutherland (Sita and Draupadi: Aggressive Behavior and Female Role-Models in the Sanskrit Epics, 1989) y Madhu Kishwar (Yes to Sita, No to Rama: The Continuing Hold of Sita on Popular Imagination in India, 2000).

Si Sītā representa un ideal femenino "moderno", que se consolida en época del Hinduismo y se proyecta hacia la sociedad contemporánea, Ambā, por el contrario, remite a un ideal femenino "antiguo", que se remonta a época del Vedismo. Ahora bien, dicho ideal se concreta en un contexto propiamente hindú: en una obra de smrti (tradición memorizada), en la cual el saṃāara (ciclo de las reencarnaciones) y el tapas (ascetismo) desempeñan un papel crucial.

\section{Hinduismo y vedismo}

En sentido amplio, el hinduismo se refiere a la pluralidad de creencias y prácticas religiosas, sociales y culturales durante el período épico y purāṇico (500 a. C.-500 d. C.), mientras que el vedismo alude a dichos fenómenos en el denominado período védico (1500500 a. C.) (Flood, 2008, p. 39).

En el hinduismo, el ideal femenino posee un componente físico y uno actitudinal. De este modo, la belleza se complementa con la conducta apropiada, según prescripciones religiosas, sociales y culturales. Desde la óptica religiosa, el culto al principio femenino (García-Ormaechea, 2006, p. 369) está documentado en la India desde la cultura del Valle del Indo (2500-1500 a. C.). Allí, las representaciones, como el Torso femenino de Harappa (2000 a. C.), pese a no contar con gran nivel de detalle, poseen un simbolismo significativo: la mujer vinculada a la maternidad, la danza asociada a la creación. A su vez, desde la perspectiva socio-cultural, el ideal de belleza femenina aparece ya en época Maurya (322-185 a. C.), por ejemplo, en la Yakșī de Didarganj (c. 200 a. C.), donde, como se constata mediante el cauri (espantamoscas), se asocia específicamente a la realeza.

En la época hindú, el acontecimiento más significativo en la vida de las mujeres es el matrimonio. Se casan con hombres mucho mayores y tienen como meta última tener hijos, de preferencia varones. El Arthaśāstra (s. II a. C. - s. III d. C.) fija como la edad más conveniente los doce años, pero la Manusmrti (s. II a.C. - s. III d.C.) aconseja los ocho años.

La Manusmrti (III, 20-34), que desde su publicación (Bengala, 1794, traducción de Sir William Jones) sirvió como digesto de la legislación hindú (Vanita, 2003, p. 77), tipifica los matrimonios en ocho clases:

\footnotetext{
1) brāhma vivāha (matrimonio del creador): la novia es entregada por su padre a un hombre de la misma casta junto con una dote.

2) daiva vivāha (matrimonio de los dioses): la novia es entregada por su padre al sacerdote oficiante sin una dote.

3) arșa vivāha (matrimonio de los videntes): la novia es entregada por su padre y este recibe vacas como regalo del novio.
} 
4) prajāpatya vivāha (matrimonio del señor): la novia es entregada por su padre y este ofrece honores al novio.
5) asura vivāha (matrimonio de los demonios): la novia es entregada por su padre y este recibe dinero como regalo
del novio.
6) gāndharva vivāha (matrimonio de los músicos celestiales): la novia y el novio deciden casarse y obtienen el
consentimiento de los padres.
7) rakșasa vivāha (matrimonio de los demonios perpetradores de engaños): la novia es raptada por el novio y este
destruye su hogar y mata a su familia.
8) paiśáca vivāha (matrimonio de los demonios devoradores de carne): la novia es raptada por el novio mientras está
dormida, intoxicada o fuera de sus facultades (adaptado de Bühler, 1886).

Para los seis primeros tipos de matrimonio, una serie de fórmulas acompañan el ritual. Tomados de la mano, el novio dice: "Yo cojo tu mano con la esperanza de felicidad, a fin de que tú vivas conmigo, tu marido, hasta una edad avanzada. Los dioses te han entregado a mí para que podamos dirigir nuestro hogar" (Auboyer, 1974, p. 211). Atados sus vestidos, el novio agrega:

Yo soy él, tú eres ella, tú eres ella, yo soy él; yo soy el cielo, tú eres la tierra; yo soy el canto, tú la estrofa. Ven, que vamos a unirnos y a traer niños al mundo. ¡Amantes, todos los que gozáis, corazón alegre, que nosotros podamos vivir cien otoños! (Auboyer, 1974, p. 211).

Para sellar su unión, dan juntos siete pasos y proclaman: "Da un paso para el alimento, dos para la fuerza, tres para que crezcan las riquezas, cuatro para la suerte, cinco para los hijos, seis para las estaciones y siete pasos para que seas mi amiga" (Auboyer, 1974, p. 211). Luego, marchan a su casa, donde la novia evita pisar el umbral a la entrada. Después de tres días de ayuno, consuman su unión. La última de las fórmulas reza así: "Unidas están nuestras almas, unidos nuestros corazones, unidos nuestros cuerpos. Yo me comprometo a amarle; que ello sea indisoluble" (Auboyer, 1974, p. 212).

Las dos últimas formas de matrimonio (el rapto con violencia y el rapto con abuso), que en la legislación actual corresponderían a delitos, son desaconsejadas en el caso de los brahmanes (sacerdotes), debido a la impureza que conllevan. No obstante, una de ellas (el rapto con violencia) es permitida para los kșatriyas (guerreros), pues permite que los héroes prueben su valía.

En la práctica, existen también otros tipos de matrimonio que no aparecen codificados. Entre ellos, cabe destacar, por una parte, el svayamvvara (matrimonio por elección), en el cual la novia elige al novio entre un grupo de pretendientes. A esta pertenecen, por ejemplo, el matrimonio de Damayantī, en la famosa interpolación, y el de la propia Draupadī, en la historia central del Mahābhārata. Por otra parte, el niyoga (matrimonio por asignación) consiste en un nuevo matrimonio de la mujer que ha enviudado y se suele manejar dentro de la propia familia.

\footnotetext{
Según esta ley, estaba obligada, bajo pena de castigo grave, a casarse inmediatamente después de la muerte de su esposo con el pariente más próximo del marido, generalmente con uno de sus hermanos, incluso en el caso de que ya estuviera casado, o en el caso de que no tuviera parientes, con un brahmán escogido por su suegro y la familia del difunto. Esta costumbre, destinada a asegurar la descendencia de la familia, es probablemente el resultado de las reglas de sucesión; se ha visto en ella una muy probable supervivencia del levirato que estaba en vigor en los tiempos antiguos (Auboyer, 1974, p. 223).
}

En el hinduismo, las mujeres se encuentran en una posición subordinada con respecto a los hombres: antes del matrimonio, dependen de su padre; después del matrimonio, de su esposo, y, en caso de enviudar, de sus hijos varones (Manusmrti, IX, 3). El único espacio en el que cuentan con cierta equidad es el hogar, cuya administración constituye su tarea principal: limpiar la vivienda, preparar la comida, criar a los hijos y administrar las finanzas. Todo esto lo hacen por amor y fidelidad a sus esposos. En este sentido, la literatura de época hindú, como 
el Mahābhärata y el Rāmāyaṇa, presenta a "la mujer como el ideal de la virtud de todas las cosas: ella es fiel, amante y valerosa" (Auboyer, 1974, p. 196).

Ahora bien, en el vedismo, la situación es, en términos generales, más favorable para las mujeres. Los textos literarios de época védica evidencian que "la mujer gozó de una envidiable libertad, que poseía más o menos los mismos derechos que el hombre y que incluso dentro del hogar le era superior" (Auboyer, 1974, p. 196). En el propio Mahābhärata (I, 113), el rey Pāṇụu le cuenta a su esposa Kuntī sobre una época antigua, en la cual las mujeres gozaban de mayor independencia. En cuanto al matrimonio, el $\operatorname{Rg} \operatorname{Veda}(\mathrm{X}, 85)$ "revela, para la mujer casada, una posición de privilegio que más adelante le iba a ser negada" (Vofchuk, 2016, p. 117) y, en relación con la maternidad, el mismo $R g$ Veda posee pasajes (II, 39, 6) que enfatizan la función nutricia. En lo que concierne a las labores domésticas, cabe destacar que la grhapatn̄̄ (señora de la casa) ocupa una posición próxima a la del grhapati (señor de la casa) (De Mora y Jarocka, 1974, p. 71).

Como bien ha apuntado Raman (2009, p. 23),

En torno al 500 a.C., los patriarcas sánscritos comenzaron a descontinuar el upanayana de las mujeres, el cual les permitía aprender los Vedas y dirigir los fuegos rituales. En tanto el conocimiento es conmensurable con el poder, las mujeres en la India sufrieron, por tanto, un importante contratiempo.

Esta iniciación ritual, suerte de segundo nacimiento simbólico, marca la incorporación de los varones brahmanes (sacerdotes), kșatriyas (guerreros) y vaiśyas (agricultores-ganaderoscomerciantes) a la comunidad ärya (noble) (Lorenzen y Preciado, 1996, pp. 37-38).

La religión védica celebra, en el plano divino, a las diosas Dhī (Inspiración) y Vāc (Palabra) como fuentes de creación de enorme poder. Por su parte, la sociedad védica contempla la participación, en el ámbito humano, de yajamānyaḥ (mujeres sacrificadoras), hotryah (mujeres oficiantes), brahmavādinyah (mujeres eruditas), ācāryānyah (mujeres maestras) y upadhyāyānyah (mujeres preceptoras) y rșikāh (mujeres ascetas) (Raman, 2009, pp. 30-32). De hecho, en Brhad-devatā (II, 89-91) se mencionan 27 videntes femeninas que habrían sido autoras de himnos védicos (Chaudhuri, 2001, p. LXXXIX). Esta fuerte presencia en actividades públicas y privadas habría decaído hacia el año 200 a. C. (Raman, 2009, p. 31).

En el tránsito del vedismo al hinduismo, ocurren dos fenómenos paralelos: a nivel social, las mujeres indias pierden parte de su libertad y se ven sometidas a la autoridad masculina; a nivel literario, esta posición de sometimiento se legitima a través de personajes femeninos idealizados como modelos de fidelidad. Así, el Mahābhārata presenta, en cuanto a la imagen de las mujeres, una doble faceta (Kalyanov, 1977-1978, p. 161): su descripción poética y artística, por un lado, y su estatus en la sociedad dominante, por otro.

\section{Mahābhārata}

El ideal femenino se aprecia, en el Mahābhärata, tanto en palabras como en acciones. Con respecto a las primeras, destacan los epítetos referidos a personajes femeninos; en relación con las segundas, sobresalen las diferentes narraciones insertadas protagonizadas por personajes femeninos.

Los epítetos en el Mahābhārata (Kalyanov, 1977-1978, p. 162) resumen el que sería el ideal, tanto en términos de belleza física como en cuanto a dignidad moral: sobre la sonrisa, cāruhāsin̄ (de dulce sonrisa), susmitā (de sonrisa brillante); sobre la cintura, sumadhyamā (de cintura hermosa y delgada); sobre los muslos, prthuśroṇ̄ (de muslos bien formados), varārohā 
(de muslos redondeados), vāmorū (de muslos hermosos); sobre los ojos, sulocanā (de hermosos ojos), āyatalocanā (de ojos grandes), cārulocanā (de ojos encantadores), kamalekșaṇa (de ojos de loto); sobre el rostro, śubhanānā (de rostro agradable); o sobre su comportamiento, priyavādin̄̄ (de conversación agradable), dharmacāriṇ̄ (de inclinación religiosa), gajagāmin̄̄ (que camina con paso de elefante). Este último resulta halagüeño en el contexto indio, donde el elefante es apreciado por su majestuosidad.

Los personajes femeninos del Mahābhārata se caracterizan por la simplicidad y el encanto; por la tenacidad, la entrega y el coraje; por la devoción y la honestidad; por la inteligencia y la sabiduría; por la perseverancia en su propósito y la independencia en su accionar, y, de manera muy especial, por su rol activo en el desarrollo de los acontecimientos. Śakuntalā, Śarmișthā, Draupadī, Damayantī, Sāvitrī, Gāndhārī y Sulabha son, como Ambā, ejemplos de personajes femeninos que resultan protagónicos en ciertas secciones de la epopeya.

Śakuntalā $(M B h$. I, 68, 1-8) era una ermitaña que se casó con el rey Dușyanta. Para acceder al matrimonio, puso al rey la condición de que hiciera heredero a su hijo, Bharata, quien se convirtió en el antepasado común de la dinastía de las Bhāratas. A ella pertenecen tanto los Pāṇụavas como los Kauravas, los dos bandos de primos que se enfrentan en la gran guerra.

Śarmișțā (MBh. I, 76-80) era una sirvienta que se casó con el rey Yayāti. Pese a ser sirvienta de la reina, convenció al rey de un segundo matrimonio con ella. El rey Yayāti tuvo cinco hijos: dos con su primera esposa, Devayān̄̄, y tres con su segunda esposa, Śarmișthā. El hijo menor de esta segunda unión, Puru, es otro antepasado de la dinastía de las Bhāratas.

Draupadī (MBh. I, 175-182) era una princesa que se casó con los cinco hermanos Pāṇụavas. Arjuna, quien la había conseguido tras vencer en el certamen del arco, le cuenta a su madre Kuntī que obtuvo un premio; esta, sin saber que se trataba de una esposa, le manda compartirlo con sus hermanos. El matrimonio de Draupadī resulta interesante por al menos dos motivos: por una parte, representa un caso de svayamvara (matrimonio por elección) en el cual se limita la capacidad de elección de la novia, lo que ha llevado a algunos autores (Alam, 1994, p. 1519, traducción propia) a considerar esta forma de matrimonio, en términos generales, como "una burla poética de la libertad de las mujeres"; por otra parte, constituye un caso excepcional de poliandria (frente a la más habitual costumbre de la poligamia). En la historia central del Mahābhārata, Draupadī fue injuriada al ser forzada a aparecer en público durante su período menstrual y ser apostada en un juego de dados. Con todo, se mantuvo fiel a sus esposos, incluso durante los doce años de exilio, lo que la ha convertido en una especie de "ideal de mujer india" (Kalyanov, 1977-1978 p. 165, traducción propia).

Damayantī $(M B h$. III, 51, 29) era una princesa que se casó con el príncipe Nala. En su svayamvara (matrimonio por elección), prefirió a un esposo mortal, cuando hasta los mismos dioses se hallaban entre sus pretendientes. El de Damayantī es un caso de upākhyāna (historia explicativa), que el sabio Mārkaṇdeya cuenta a Yudhișțhira, a modo de ejemplo de fidelidad femenina. En este sentido, Damayantī suele ser considerada como "ideal de fidelidad de una esposa" (Kalyanov, 1977-1978, p. 165, traducción propia).

Sāvitrī (MBh. III, 278, 10, 26-27) era una princesa que se casó con el príncipe Satyavāt. Eligió a su esposo a sabiendas de que moriría al cabo de un año y, posteriormente, lo salvó de la muerte mediante sus discursos ante el dios Yama. También como upākhyāna (historia explicativa) cuenta el sabio Mārkaṇḍeya la historia de Sāvitrī a Yudhișțhira, para reforzar la idea de fidelidad. Sāvitrī es considerada la pativratā (esposa devota) por antonomasia (Shah, 
2012, p. 82), al punto de que esta interpolación recibe el nombre de Pativratā Māhātmya $\bar{A} k h y \bar{a} n a$ (Episodio de la glorificación de la esposa devota).

Gāndhārī (MBh. XI) era una princesa que se casó con el rey Dhṛtarāșțra. Decidió cubrirse los ojos el día de su matrimonio, para compartir la ceguera de su esposo. Entre las mujeres fieles, Gāndhārī destaca por ciertos rasgos de "rebeldía" (Alam, 1994). Por ejemplo, el hecho de haber lanzado una maldición sobre Kṛ̦ṇa, tras enterarse del engaño que había mediado en la muerte de su hijo Duryodhana. Además, no se limita a las labores del hogar, sino que, dada su ceguera voluntaria, ve más allá del horizonte, como los poetas (Alam, 1994, p. 1519).

Finalmente, Sulabha (MBh. XII) era una rșikā (mujer asceta) y, en consecuencia, no estaba casada. Defendió con argumentos la igualdad entre hombres y mujeres, durante un debate que sostuvo con el rey Janaka. Efectuó su argumentación, "con base en principios filosóficos hindúes" (Vanita, 2003, p. 76, traducción propia). Cabe destacar que Sulabha es considerada la "mujer erudita por excelencia" (Vanita, 2003, p. 79, traducción propia).

Los primeros cinco personajes femeninos referidos tienen en común el estar casadas. Más aún, su papel protagónico va en función de sus respectivos matrimonios, en uno de dos posibles sentidos: el linaje que originan (Śakuntalā, Śarmișthā) o los esposos que acompañan (Draupadī, Damayantī, Sāvitrī). Gāndhārī se distingue del grupo, pues, estando casada, no solo influye en los acontecimientos relacionados con su esposo, sino también en los del bando contrario, incluso después de la guerra. Sulabha, por su parte, destaca porque no está casada, pero, principalmente, en tanto defiende un punto de vista con sus propias palabras. Esta forma de autonomía está presente también en Sāvitrī, quien, con sus discursos, salva a su esposo.

Con respecto a Sulabha, Vanita (2003, p. 78, traducción propia) sostiene que "tras la figura de la mujer autónoma e instruida se yergue la figura de la diosa autónoma que preside la instrucción". En efecto, la mitología hindú atribuye el ámbito del conocimiento y la sabiduría, de las artes y las letras, a la diosa Sarasvatī. En la iconografía, esta divinidad presenta cuatro brazos (como las cuatro cabezas de su esposo Brahmā), con sendos atributos: el pustakam (manuscrito), simboliza los Vedas; la mālā (guirnalda de cuentas de cristal), la meditación; el jalam (agua), la purificación, y la vīnā (instrumento de cuerdas), las artes.

La asceta Sulabha y el rey Janaka entablan un kathā (debate), práctica que se remonta, en la India antigua, al jalpa (sofistería) de las escuelas de pensamiento rivales. En los textos hindúes, los debates cumplieron una función organizadora de ideas filosóficas (Vanita, 2003, p. 80), de manera análoga a lo ocurrido con los diálogos platónicos.

El Mahābhārata, con sus extensas conversaciones sobre diversos temas, no es ajeno a estas prácticas argumentativas. El debate de Sulabha y Janaka versa, no solo sobre los caminos hacia la liberación, sino también sobre las particularidades del género (Vanita, 2003, p. 80): la autonomía de la mujer, la capacidad intelectual de la mujer e, incluso, las posibilidades de la mujer de alcanzar la liberación.

En el texto, Janaka pregunta a Sulabha quién es, de quién es, de dónde viene y a dónde va. Entre la serie de preguntas, que traen a la memoria de cualquier estudioso de los clásicos las fórmulas homéricas de hospitalidad, llama especialmente la atención la segunda: se presupone que la mujer le pertenece a algún hombre. Como se ha visto, no es ese el caso de Sulabha, quien ha optado por una vida de ascetismo, celibato e instrucción.

Janaka argumenta (Vanita, 2003, pp. 83-84) (1) que él es superior a los renunciantes; (2) que los renunciantes pueden estar apegados al mundo y los reyes pueden no estar apegados al mundo, y (3) que Sulabha, como mujer, está apegada al mundo, mientras que él, como rey, 
no está apegado al mundo. Una de las proposiciones es verdadera: ciertamente, puede haber renunciantes apegados o reyes desapegados (segunda). No obstante, las otras dos son falsas: una mujer no es apegada a lo material, por el hecho de ser mujer (tercera). Eso es solo un prejuicio $\mathrm{y}$, si alguien tiene prejuicios, no está desapegado de lo material (primera).

Sulabha basa su contraargumentación en la gramática. El hombre y la mujer tienen un género, respectivamente, masculino y femenino. Pero el ātman (alma individual), que se une al brahman (alma universal) cuando se alcanza mokșa (liberación) y se abandona samsāra (ciclo de las reencarnaciones), es neutro (Vanita, 2003, p. 81) y es igual para todos los seres.

El debate revela una serie de asunciones (Vanita, 2003, pp. 87-88) sobre la condición de la mujer: si se le pregunta de quién es, se presupone que no es autónoma; si se le dice que la unión con ella no puede ser intelectual sino únicamente física, se presupone que su esencia es sexual; si se le plantean las ideas a modo de defensa, se presupone que su postura es hostil. Más que a las proposiciones, Sulabha se refiere a las asunciones que subyacen a las proposiciones. En este sentido, Sulabha constituye un modelo que apunta hacia un cambio, no de prácticas, sino de esquemas de pensamiento: "la representación de una figura femenina que gana un debate, el cual es una batalla de palabras, posiblemente funciona como un modelo más digno de imitación que la representación de una mujer que gana una batalla con armas" (Vanita, 2003, p. 91, traducción propia).

Ambā va un paso más allá: argumenta su postura, pero también actúa al respecto.

\section{4. $\quad$ El mito de Ambā}

Se procede, a continuación, a un análisis de las tres secciones del Mahābhārata (Sukthankar, Belvalkar, Vaidya, 1933-1966) en las que se desarrolla la historia de Ambā.

\subsection{MBh. I, $94-100$}

En el reino de Kurukșetra, vivía un rey llamado Śaṃtanu, único heredero del linaje de los Bhāratas y conocido por ser siempre fiel a su palabra. Un día, Śamtanu se acercó al río Ganges y encontró sus aguas quietas. El responsable de tal proeza era un muchacho de apariencia admirable. Śamtanu le pidió al Ganges que se lo mostrara y ella le reveló que se trataba de Devavrata, hijo común de ellos dos y único heredero del reino. Feliz por la revelación, Śamtanu llevó a Devavrata al palacio.

Cuatro años después, Śaṃtanu se acercó al río Yamunā y encontró una muchacha, de la cual se enamoró. Al pedir su mano a su padre, este, un pescador preocupado por la posición de su hija, le puso como condición al matrimonio que el hijo nacido de esta unión fuera el próximo rey. Śamtanu, preocupado por el futuro de su hijo, decidió regresar a casa. Al notar la preocupación de su padre, Devavrata preguntó su causa al consejero de palacio y decidió actuar para arreglar la situación.

Devavrata fue en persona a pedir la mano de Satyavatī, la hija del pescador, para su padre. El pescador mostró su disposición, pero volvió a mencionar su condición. Devavrata, decidido a ayudar a su padre, aceptó renunciar no solo al reino, sino también a tener descendencia, con lo cual aseguraba la sucesión de un eventual hijo de Śamtanu con Satyavatī. Ante tal acto de sacrificio, incluso los dioses exclamaron "Bhīṣma (asombroso)", nombre con el que procedió a ser conocido Devavrata. A su regreso, Śamtanu le confirió una gracia de valor semejante a la recibida: Bhīṣma sería invencible en combate y solo moriría cuando él así lo deseara. 
Śaṃtanu tuvo con Satyavatī dos hijos, Citrāngada y Vicitravīrya. A la muerte del rey, Bhīṣma entregó el trono a Citrāngada, quien lo ocupó hasta su propia muerte, ocurrida en una batalla contra los Gandharvas. Entonces, Bhīṣma entregó el trono a Vicitravīrya, quien a causa de su corta edad, tuvo a Bhīṣma como su regente. Cuando Vicitravīrya alcanzó la edad adulta, Bhīṣma decidió, previa aprobación de Satyavatī, buscarle esposa.

Bhīṣma viajó a la ciudad de Benarés, donde las tres hijas del rey de Kāśis, llamadas Ambā, Ambikā y Ambālikā, según la costumbre del matrimonio por elección de la mujer, habían de elegir a sus respectivos esposos. Bhīṣma, tras declarar que la mejor de las formas de matrimonio es el rapto, forzó a las tres princesas a subir a su carruaje y retó a todos los guerreros del reino a hacerle frente. Colmados de ira, los guerreros se enfrentaron a Bhīṣma, pero fueron derrotados. Siguiendo el kșatradharma (deber del guerrero; MBh. I, 96, 29, 1), Bhīṣma aceptó finalmente un duelo singular con el rey Sālva, tras el cual selló su victoria definitiva. Luego, se llevó a las tres muchachas, a las que trató como si fueran sus propias snuṣās, anujās, duhitaras (nueras, hermanas menores, hijas; MBh. I, 96, 44, 1-2).

De acuerdo con la tipología de los matrimonios expuesta, Ambā, Ambikā y Ambālikā iban a casarse por svayaṃvara (matrimonio por elección), pero Bhīṣma las tomó según el rakșasa vivāha (matrimonio de los demonios perpetradores de engaños), pues las muchachas se encontraban en plenitud de sus facultades y el rapto fue seguido por un enfrentamiento. El matrimonio por elección se presta, como en el caso de Draupadī, para el certamen como espacio para probar el valor del vīra (héroe), sin afectar (al menos según la tradición hindú) la integridad de la $s t r \bar{\imath}$ (mujer). En cambio, el matrimonio por rapto, si bien brinda testimonio del heroísmo de Bhīṣma en tanto kșatriya (guerrero), constituye también una afrenta hacia las muchachas.

Tal es, precisamente, la postura de Ambā, la mayor de las hermanas, quien en un breve discurso plantea su punto de vista y lo justifica de manera suficiente para convencer a Bhīṣma de dejarla partir. El discurso de Ambā es el siguiente:

\footnotetext{
mayā saubhapatih pūrvam manasābhivṛtah patih

tena cāsmi vṛtā pūrvam eșa kāmaśca me pituh

mayā varayitavyo 'bhūcchālvastasmin svayamvare

etad vijñāya dharmajña tatastvam dharmam ācara.

Ya por mi opinión fue elegido como esposo el rey de Saubha, ya por él fui elegida; y este era el deseo de mi padre. Por mí, resultó elegido Śālva en este svayamvara. Conociendo esto, oh conocedor del dharma, entonces practica tú el dharma (MBh. I, 96, 48, 1 - 49, 2, traducción propia).
}

El discurso defiende, desde el punto de vista de la legalidad, el svayamvvara (matrimonio por elección). Las formas verbales utilizadas empleadas al inicio comparten el sentido de elección: VR (elegir) y abhi-VR (elegir). Se enfatiza la reciprocidad de dicha elección: Śālva ha sido elegido mayā manasā (por mi opinión) y Ambā lo ha sido tena (por él). Y se alude a la anterioridad del acuerdo: ambas partes han elegido pūrvam (ya). Así, al ser el matrimonio por elección previo al matrimonio por rapto, este último queda invalidado.

Dos factores legitiman la elección de Ambā: el manas (opinión) propio y el kāma (deseo) paterno. Si bien la autorización paterna es requerida en un contexto en el que la mujer es vista como dependiente de los hombres, también es requerido el visto bueno de la novia sobre la unión. El sánscrito manas, cognado con el latín mens, alude a la 'facultad cognitiva'. En este sentido, la racionalidad de la opinión femenina resulta, incluso, de mayor valor argumentativo que el carácter irracional del deseo masculino. 
En el nivel léxico, vale la pena destacar la ambigüedad de la voz pati (señor), la cual aparece en dos ocasiones. En la primera, referida a la situación previa de Sāalva, puede ser traducida como "rey (de Saubha)". La segunda, para el contexto actual del matrimonio, admite la traducción de "esposo". El que el pati (rey) ha sido elegido como pati (esposo) es una tautología, cuya fuerza argumentativa reside, justamente, en la figura retórica denominada śleșa (ambigüedad).

La ley es clara con respecto al problema, por lo que la solución depende, únicamente, del conocimiento de la ley y de su aplicación. Las formas verbales empleadas al final apuntan hacia el conocimiento: JÑ $\bar{A}$ (conocer) y vi-JÑ $\bar{A}$ (conocer). La construcción con absolutivo etad vijñāya (conociendo esto) corresponde al upanaya (recapitulación) del silogismo hindú. A su vez, el epíteto dharmajña (conocedor del dharma) permite, a través de la repetición de raíces pertenecientes al campo semántico del conocimiento, relacionar la situación de Ambā, que corresponde al dharma en su acepción de 'ley social', con la actuación de Bhīṣma, que atañe al dharma en cuanto 'deber moral'.

Si Bhīṣma se apega al dharma (deber), debe estar de acuerdo en que el matrimonio de Ambā es conforme al dharma (ley). Así, el nigamana (conclusión), introducido por el marcador discursivo tatas (entonces), sería que Bhīṣma sea consecuente y actúe conforme a sus creencias. La capacidad de convencimiento de las palabras de Ambā se debe a que no justifica su opinión desde su propio punto de vista, sino desde el de su interlocutor.

Habiendo convencido a Bhīṣma, Ambā regresó con Śālva. Ambikā y Ambālikā, por su parte, fueron desposadas por Vicitravīrya, quien tan solo siete años después murió sin haber dejado descendencia. Entonces, Satyavatī, deseosa de preservar el linaje, apeló al āpaddharma (ley de la angustia). De acuerdo con Dhand (2004, p. 39, traducción propia), este comporta todas aquellas "prácticas que, pese a no ser exactamente honorables o virtuosas, pueden, con todo, realizarse con impunidad en caso de absoluta necesidad”. Así pues, Satyavatī pidió a Bhīṣma que tuviera él hijos con Ambikā y Ambālikā. Sin embargo, Bhīṣma, fiel a su palabra, le recordó su voto de castidad.

Como contrapropuesta, Bhīṣma recurrió al upākhyāna (historia explicativa) de Utathya, un brahmán que había dado descendencia a un rey que no podía tenerla. ¿Por qué no buscar la ayuda de un brahmán para dar continuidad al linaje de los Bhāratas? Entonces, Satyavatī le reveló que, siendo ella joven, el sabio Parāśara, a quien ella llevara en su barca a través del río Yamunā, la había poseído y que, todavía siendo ella virgen, de dicha unión había dado a luz a Dvaipāyana, al que llaman Vyāsa (compilador de los Vedas).

Dispuesto a ayudar, Vyāsa se presentó al palacio y Satyavatī, siguiendo el consejo de Bhīṣma, apeló al niyoga (matrimonio por asignación). En opinión de Dhand (2004, p. 38, traducción propia), este "permitía que una mujer obtuviera hijos por mediación de otro hombre, si su esposo había fallecido, era infértil o estaba incapacitado de alguna otra manera". De este modo, Ambikā y Ambālikā se probarían dignas de su kula, prasava (linaje, descendencia; MBh. I, 99, 35, 2).

Vyāsa solicitó un período de un año para la consagración de las muchachas, pero, ante la premura de Satyavatī, aceptó yacer con ellas de inmediato, si ellas toleraban el mal olor y la desagradable apariencia característicos de un asceta. La primera en recibirlo fue Ambikā, quien, asustada por su pelo y su barba rojizos, cerró los ojos. En consecuencia, el hijo nacido de ella, Dhṛtarāșțra, sería ciego. La segunda fue Ambālikā, la cual palideció a la vista de Vyāsa. Por ello, el hijo nacido de ella, Pāṇụu (pálido), tendría dicha apariencia. Por último, Ambikā, 
reacia a yacer nuevamente con el sabio, envió a su esclava, de la cual nacería Vidura. Con el paso del tiempo, de Dhṛtarāṣtra nacerían los Kauravas y de Pāṇụu los Pāṇḍavas, entre los cuales llegaría a surgir la disputa por la sucesión en el reino.

Esta primera sección del relato presenta a Ambikā y Ambālikā como madres de las dos ramas en que se bifurca el linaje de los Bhāratas. Por el contrario, evidencia a una Ambā decidida a cumplir con rol como esposa, pero del hombre que ella había elegido. En sánscrito (Monier-Williams, 2008, p. 83), ambāa, ambayā, ambā dāa, ambālā, ambālikā, ambālì, ambikā y $a m b \bar{\imath}$ son términos que remiten a $a m b \bar{a}$, cuyo sentido es el de 'madre' o el de 'buena mujer', y cuyo uso se generalizó al punto de convertirse en un título de respeto. Si Ambikā y Ambālikā son las madres que traen al mundo a los herederos de la dinastía, Ambā es la buena mujer que, como Sītā, regresa con su esposo.

\subsection{MBh. V, 170-197}

Años después, durante la batalla de Kurukșetra, Duryodhana, el nieto de Bhīṣma, le pregunta a su abuelo la razón por la cual no está dispuesto a matar al guerrero Sikhaṇdin. Bhīṣma recapitula los hechos y prosigue con el relato de Ambā.

Liberada por Bhīṣma, Ambā regresó ante el rey Śālva, quien la consideró una anyapūrvā (mujer prometida primero a un hombre y casada después con otro; $M B h$. V, 172, 4, 2) y la rechazó tvacam jīrṇām ivoragah (como una serpiente a su piel muerta; $M B h$. V, 172, 17, 2). Despreciada por Śālva, Ambā reflexionó sobre la causa de su infortunio: ¿era culpa de su padre, por exponerla a ser tomada?; ¿de su captor, por llevársela a la fuerza?; ¿de sí misma, por no bajar del carro?; ¿de su prometido, por no recibirla de vuelta? Finalmente, llegó a la conclusión de que el verdadero culpable era Bhīṣma.

Ambā opta por prati-KR (vengar; $M B h . \mathrm{V}, 173,8,1)$ su agravio. De la preposición prati (de vuelta) y la raíz KR (hacer), se forma el sustantivo pratikāra (venganza), que, etimológicamente, vendría a ser 'devolución', tanto en el sentido positivo de 'retribución' como en el negativo de 'represalia'. Ambā ve la afrenta, no en el matrimonio por rapto del cual ha sido liberada, sino en la afectación que este tuvo sobre el matrimonio por elección en el cual todavía querría tomar parte. La afrenta ha interferido con su matrimonio, esto es, con su propósito en la vida. Así, si Bhīṣma ha acabado con su vida como mujer, ella acabará con la vida de él como guerrero.

Ambā halló, para su venganza, dos vías: tapasā vā yudhā (con ascetismo o con batalla; $M B h . \mathrm{V}, 173,8,2$ ). Dada la fama de Bhīṣma en batalla, optó por la primera de ellas y pidió a unos ascetas que la instruyeran en sus prácticas. La mayoría de los ascetas trataron de disuadirla: si su prometido la había rechazado, su padre la aceptaría, pues patir vāpi gatir nāryāh pitā vā (o el esposo o el padre es el recurso de la mujer; $M B h . \mathrm{V}, 174,7,1)$. Solo el sabio Hotravāhana, su abuelo materno, secundó la venganza, para lo cual le aconsejó pedir ayuda al sabio Rāma Jāmadagnya.

A petición de Ambā, Rāma Jāmadagnya, quien había sido el preceptor de Bhīṣma, retó a su discípulo a un duelo. El combate se extendió por varios días, hasta que unos brahmanes se aparecieron a Bhīṣma en un sueño y le revelaron un arma que haría dormir a Rāma Jāmadagnya. Cuando Bhīṣma se dispuso a usarla, hasta los dioses se interpusieron para evitar una ofensa innecesaria y obligaron a ambos combatientes a retirarse. Entonces, Ambā decidió seguir el camino del ascetismo con el fin de obtener por cuenta propia la 
victoria. A su vez, Bhīṣma encargó a sus hombres que siguieran el rastro de esta mujer, a la cual empezó a considerar como una amenaza.

Catorce años duraron las austeridades de Ambā: no consumir alimentos, no cuidar de su apariencia, mantener posturas difíciles, visitar lugares de peregrinación. El río Ganges, madre de Bhīṣma, trató de disuadirla de su empeño. Le advirtió que, por su sinuoso pensamiento, se convertiría en un río sinuoso, seco durante todo el año (excepto por la época del monzón) y lleno de cocodrilos. Eso fue lo que sucedió: del cuerpo de Ambā, la mitad se convirtió en un río y la otra mitad mantuvo su forma humana. Nadie podía desviar a Ambā de su meta.

La respuesta de Ambā a la pregunta acerca de su empeño era que, perdido su esposo, había perdido su identidad como mujer: patilokād vihīnā ca naiva strī na pumān iha (perdido el mundo del esposo, ahora ni mujer ni hombre; $M B h . \mathrm{V}, 188,4,2)$. En consecuencia, la princesa había decidido dejar de ser mujer y convertirse en hombre: strībhāve parinirvinnnā pumstvārthe krtaniśscayā (disgustada en extremo con la condición de mujer, estoy decidida a alcanzar la condición de hombre; $M B h$. V, 188, 6, 1). A este punto, el dios Śiva le concedió, a causa de su fervor ascético, dos dones: reencarnar como hombre y matar a Bhīṣma. Deseosa de venganza, Ambā edificó una pira y, uktvā bhīṣmavadhāyeti (habiendo hablado así: "para la muerte de Bhīṣma"; MBh. V, 188, 18, 1), se arrojó al fuego.

Ambā, cuyo propio nāman (nombre) apunta a la maternidad como un deber femenino, asimila la imposibilidad de su matrimonio de Sâlva a la inviabilidad de una vida como mujer. Perdido el esposo, perdida la vida. Por consiguiente, se lanza a una satī (inmolación de la viuda) que es preciso leer en toda su dimensión irónica: Ambā no sube a la pira con Bhīṣma, sino sola; Bhīṣma no está muerto, sino vivo; y Ambā no lo va a acompañar pasivamente al reino de los muertos, sino que lo va a enviar allí a través de su acción.

La inversión de Ambā a este punto de la narrativa presenta una doble faceta: de un rol pasivo a uno activo mediante la inmolación y, como consecuencia, de un género femenino a uno masculino para efectos de su venganza. En su profundo análisis sobre el género en la Antigüedad griega e india, Doniger (1999, p. 281, traducción propia) apunta que "la transformación de mujeres en hombres es, a la vez, más rara y mucho más destructiva que la transformación de hombres en mujeres", debido, entre otras cosas, a que los hombres suelen transformarse en mujeres como resultado de una maldición, mientras que las mujeres frecuentemente lo hacen por elección.

Tiempo después, un rey llamado Drupada, quien no había podido tener un hijo, se sometió a austeridades y buscó el favor del dios Śiva. Este estuvo dispuesto a darle una hija, que después se convertiría en un hijo. Así, tras el nacimiento de la niña, Drupada realizó todos los ritos como si se tratara de un niño y Śikhaṇịin̄ (nombre femenino) fue conocida como Śikhaṇdin (nombre masculino). Etimológicamente (Monier-Williams, 2008, p. 1070), Śikhaṇdin es el 'que lleva un penacho o un mechón de pelo'. Tales atributos caracterizaban a los hombres guerreros, por lo que el propósito del nuevo nombre es recalcar la nueva función del individuo en la sociedad.

Śikhaṇụin̄i alcanzó la madurez sin haber cambiado de sexo. Aun así, convencido por su esposa y confiado en la palabra del dios, Drupada la casó con la hija del rey aliado Hiranyavarman. Este, al enterarse de la situación, amenazó con una guerra. Ante tal peligro, Śikhaṇdinī optó por quitarse la vida. Se dirigió al bosque, donde encontró un yakșa (espíritu de la naturaleza) que ofreció cumplirle cualquier deseo que tuviera. Śikhaṇdinī aprovechó la oportunidad para pedirle que la convirtiera en hombre. 
El yakṣa accedió con una condición: cambiaría su propio puṃlingam (órgano masculino; $M B h$. V, 193, 2, 2) por el strīlingam (órgano femenino; $M B h$. V, 193, 4, 1) de la muchacha, si luego de evitar la guerra entre los reyes aliados ella regresaba para hacer de nuevo el intercambio. Sin embargo, Kubera, dios de la riqueza y rey de los yakșas (espíritus de la naturaleza), enojado lo maldijo a permanecer como mujer, hasta que Śikhaṇdin muriera en batalla. Así, Śikhaṇdin no solo logró poner fin a la querella entre reyes, sino que también pudo conservar su forma masculina.

Bhīṣma, terminado el relato, enfatiza su promesa de no dirigir sus flechas contra striyām strīpūrvake cāpi strīnāmni strīsvarūpiṇi (una mujer, alguien que antes fue mujer, alguien con nombre de mujer o alguien con apariencia de mujer; MBh. V, 193, 62, 2). Esta no le permite pelear contra Ambā-ŚSikhaṇdin, a quien considera un strīpumān (mujer-hombre; MBh. V, 193, 59, 1).

Esta segunda sección del relato desarrolla la transformación de Ambā. De su tendencia a lo doble (Doniger, 1999, p. 284) hablan su metamorfosis parcial (río-mujer), su reencarnación (Ambā- Śikhaṇḍinī) y su cambio de sexo (Śikhaṇḍinī-Śikhaṇḍin). En sánscrito (MonierWilliams, 2008, p. 630), puṃlingam significa tanto ‘órgano masculino' o 'género masculino', por lo que, tras el intercambio de órganos con el yakșa (espíritu de la naturaleza), Śikhaṇdin considera que ha también ha cambiado de género. No es esta la interpretación de Bhīṣma, para quien Śikhaṇdin "mantuvo su género femenino cuando perdió su sexualidad femenina" (Doniger, 1999, p. 285, traducción propia). Incluso como hombre, Ambā sigue siendo un modelo de 'mujer buena'.

\subsection{MBh. VI, 108-119}

Al décimo día de la guerra, mientras el cochero Sañjaya narra el enfrentamiento al rey ciego Dhṛtarāșțra, la historia de Śikhaṇdin llega a su fin.

Los Pāṇḍavas, sabedores de la promesa de su abuelo Bhīṣma, ubican a Śikhaṇdin en la vanguardia del ejército, como cochero de Arjuna. El propio Bhīṣma, cansado de la guerra, aconseja a Yudhiștira, el mayor de los hermanos Pāṇḍavas, poner al frente también a Arjuna, el mejor de los guerreros. Tras nueve días dirigiendo el contingente de los Kauravas, Bhīṣma decide, al décimo día, no luchar más, por un lado, por tratarse de los Pāṇḍavas, a quienes tiene en alta estima; y, por otro, por tener como enemigo a Śikhaṇdin, quien otrora fuera Ambā.

Bhīṣma recuerda las promesas de su padre (ser invencible en combate y morir cuando quisiera). Entonces, tras las flechas de Śikhaṇdin, que no lograron herirlo, recibe también las flechas de Arjuna, que lo tumban de su carruaje. Tal es la cantidad de flechas que lo perforan que no llega a tocar el suelo. En el ejemplo por antonomasia de kșatradharma (deber del guerrero), Bhīṣma yace en un lecho de flechas, a la espera de que el sol alcance un lugar propicio en el cielo para morir.

La tercera y última parte del relato, muestra la participación indirecta de Śsikhaṇdin en la muerte de Bhīṣma, con la cual se cumple el deseo de venganza de Ambā. Śikhaṇḍin morirá a manos de Aśvatthāmā cuando, terminada la guerra, los Kauravas emprendan un ataque inesperado durante la noche. Llama la atención (Doniger, 1999, p. 283) el hecho de que Aśvatthāmā, al matarlo, parta a Śikhaṇdin en dos, como una última muestra de su tendencia a lo doble. 


\section{Conclusiones}

La participación de Ambā en la trama narrativa del Mahābhārata es determinante. La venganza, a su vez, le confiere una dimensión particular. Vale la pena trazar, al menos, ciertos puntos de encuentro entre esta actividad guerrera en la épica india y una actuación similar en la épica griega, con el propósito de determinar lo específico de Ambā, tanto en el ámbito literario como en el social.

La Ilíada (XXII, vv. 214-366) narra la intervención de un personaje femenino (Atenea) que participa, indirectamente y bajo la forma de un personaje masculino (Deífobo), en la muerte de Héctor a manos de Aquiles, hecho que resulta determinante para el desenlace de la guerra de Troya. De manera análoga, el Mahābhārata (I, 94-100; V, 170-197; VI, 108-119) brinda un ejemplo de un personaje femenino (Ambā) que interviene, de forma indirecta y como un personaje masculino (Śikhaṇdin), en la muerte de Bhīṣma a manos de Arjuna, con lo que se vislumbra ya el fin de la batalla de Kurukșetra. Como señala Allen (2004, p. 35, traducción propia), "esta es la única muerte en la gran guerra que involucra, de manera crucial, a una mujer o "casi-mujer"".

La épica griega posee numerosos ejemplos de intervención divina que implican la asunción de una apariencia física distinta. Sin embargo, la transformación operada en la épica sánscrita evidencia ciertas peculiaridades propias de su contexto: Ambā es un ser humano, no una divinidad; su transformación ocurre después de una reencarnación y después de un intercambio de órganos genitales, y, quizás lo más importante, su intervención responde a un deseo de venganza, motivado por una afrenta personal.

Si Atenea-Deífobo toma parte en el final del conflicto, Ambā-Śikhaṇdin tiene un rol determinante tanto al comienzo como al final: su negativa a aceptar el matrimonio propuesto por Bhīṣma resultó en que de sus hermanas menores, asustadas por Vyāsa, nacieran herederos inapropiados (uno ciego y otro pálido), cuyos descendientes pelearían por el trono; asimismo, su deseo de venganza tuvo como consecuencia la derrota del mejor guerrero de los Kauravas, sin cuya guía la balanza se inclinaría en favor de los Pāṇḍavas.

En el nivel literario, Ambā (la madre, la mujer buena) presenta semejanzas con otros personajes femeninos del Mahābhārata. Es fiel a Śālva, aun cuando este la rechaza (como Sìtā). Se enfrenta a Bhīṣma con su discurso (como Sāvitrī) y luego se dedica al ascetismo (como Sulabha). Incluso, interviene en los acontecimientos (como Gāndhārī). Pero, el hecho de asumir la forma de Śikhaṇdin (el que lleva un penacho, el que lleva un mechón de pelo) la distingue de las demás: participa en la guerra y consigue su venganza.

En el plano social, Ambā remite al grado de libertad de las mujeres indias que habría existido en época del Vedismo y, por tanto, a un ideal femenino "antiguo". Este personaje se puede interpretar como un modelo de imitación, no solo en cuanto a cuestionar esquemas de pensamiento sobre lo que significa ser mujer, sino también con respecto a la toma de acciones para operar un cambio de mentalidades sobre la idea india de femineidad.

\section{Bibliografía}

Alam, J. (1994). Gandhari, the Rebel. Economic and Political Weekly, 29(25), 1517-1519.

Allen, N. (2004). Dyaus and Bhïma, Zeus and Sarpedon. Gaia: Revue Interdisciplinaire sur la Grèce Archaïque, 8, 29-36. 
Auboyer, J. (1974). La mujer en la India. De los orígenes al siglo XIX. En P. Grimal (Ed.), Historia mundial de la mujer Vol. III (pp. 195-298). Barcelona-México D. F.: Ediciones Grijalbo.

Bühler, G. (1886). The Laws of Manu. Oxford: Clarendon Press.

Chaudhuri, J. B. (Ed.). (2001). The Contribution of Women to Sanskrit Literature. Sanskrit Poetesses. Volume 1. New Delhi: Cosmo.

De Mora, J. y Jarocka, L. (trad.). (1974). Rgvedasaṃhitā. México, D. F.: Diana.

Dhand, A. (2004). The Subversive Nature of Virtue in the Mahābhārata: A Tale about Women, Smelly Ascetics, and God. Journal of the American Academy of Religion, 72(1), 33-58.

Doniger, W. (1999). Splitting the Difference. Gender and Myth in Ancient Greece and India. Chicago-London: The University of Chicago Press.

Flood, G. (2008). El hinduismo. Madrid: Akal.

García-Ormaechea, C. (2006). El arte de India, el Himalaya y el sudeste asiático. En J. Ramírez (Ed.), Historia del arte. Vol I (pp. 369-424). Madrid: Alianza.

Homero. (1991). Ilíada. (E. Crespo, trad.). Madrid: Gredos.

Kalyanov, V. (1977-1978). The Image of the Indian Women in the Mahābhärata. Annals of the Bhadarkar Oriental Research Institute, 58-59, 161-172.

Lorenzen, D. y Preciado, B. (1996). Atadura y liberación. Las religiones de la India. México, D. F.: El Colegio de México.

Mani, V. (1975). Purāṇic Encyclopaedia. Ned Delhi: Motilal Banarsidass.

Monier-Williams, M. (2008). Sanskrit-English Dictionary. New Delhi: Munishram Manoharlal.

Raman, S. (2009). Women in India. A Social and Cultural History. Volume 1. California: ABC-CLIO.

Shah, S. (2012). On Gender, Wives and "Pativratās". Social Scientist, 40(5/6), 77-90.

Sukthankar, V., Belvalkar, S. y Vaidya, P. (Eds.) (1933-1966). The Mahābhārata for the First Time Critically Edited. 19 Volumes. Poona: Bhandarkar Oriental Research Institute.

Tola, F. (Trad.). (1968). Himnos del Rig Veda. Buenos Aires: Editorial Sudamericana.

Vanita, R. (2003). The Self Is Not Gendered: Sulabha's Debate with King Janaka. NWSA Journai, 15(2), 76-93.

Vofchuk, R. (2016). Viudas en la India. De la antigüedad a nuestros días. Guillermo de Ockham, 14(1), 115-122. 
